\title{
Self concept and Emotional intelligence: A comparative study of Arts and Science college students
}

\author{
Dr. C. P. Labhane $_{1}$, Mr. P. A. Baviskar 2
}

\section{ABSTRACT:}

The aim of the present investigation is to study the Self concept and Emotional Intelligence perceived by college student of jalgaon dist. Sample for the study consisted of 140 between age group 18-22 years drawn from jalgaon dist. The participants were assessed with Dr. Verma and sherry Self concept scale and Dr. Upinder Dhar Emotional Intelligence scale. A t test was used to identify the significant level.

Keywords: Self concept, Emotional Intelligence Arts and Science Students.

\section{INTRODUCTION:}

Self-Concept is a term/related to the personality. Without complete development of the SelfConcept personality cannot be developed. So while studying Self-Concept, the study of personality is inevitable. Self concept is play important role in personality development. Self concept is related to emotional intelligence factor. Self concept and emotional intelligence are positively connected of human behavior. There are two most important factor was play the important role of human life.

1. Emotional intelligence -

2. Self concept -

Emotional intelligence is a dynamic construct influenced by diverse biological, psychological, and social factors. A good deal of research has been conducted on emotional intelligence and it was found to be appearing as an important factor in the prediction of personal, academic and career success. Studies on emotional intelligence with respect to various psychosocial correlates have been found in a variety of fields.

Emotional intelligence (EI) is the ability to monitor one's own and other people's emotions to discriminate between different emotions and label them appropriately, and to use emotional information to guide thinking and behavior. However, substantial disagreement exists regarding the definition of EI, with respect to both terminology and operationalizations. Currently, there are three main models of EI:

${ }^{1}$ HOD,Dept of Psychology,M.J.College,Jalgaon(MS)

${ }^{2}$ Research Fellow,Dept of Psychology, S.S.M.M.College, Pachora(MS)

(C) 2015, C labhane, P Baviskar; licensee IJIP. This is an Open Access Research distributed under the terms of the Creative Commons Attribution License (http://creativecommons.org/licenses/by/2.0), which permits unrestricted use, distribution, and reproduction in any Medium, provided the original work is properly cited. 
1. Ability model-

2. Mixed model -

3. Trait model-

- Self-concept may be defined as the totality of perceptions that each person has of themselves, and this self-identity plays an important role in the psychological functioning of everyone.

- The capacity to be aware of, control, and express one's emotions, and to handle interpersonal relationships judiciously and empathetically.

\section{REVIEW}

In their study conducted on students of Faculty Science, Engineering Faculty, College of Physical Education, Faculty of Law, Faculty of Letters, Faculty of Fine Arts and Heath Science; Erdoğdu and Kenarlı (208) determined that there are relations between academic Achievements and especially understanding own emotions and Emotion Management sub- scales of Emotional Intelligence.

Similarly Ciarrochi, chan and Bajgar (2001) found that EI was reliable measured in adolescents and was higher for females than males.

In the study reported by Uma Devi and Rayal (2004) based on gender differences among EI $(\mathrm{N}=224)$ it was revealed that seventy six percent of girls have scored EI above average. Whereas, eighty one percent of boys have scored their EI above average. This concluded that boys have scored slightly higher on their emotional intelligence as compared to their counterparts.

Dr. R. K. Yadav \& Aarti Yadav studied Value pattern \& self-concept of Arts \& Science senior secondary students. Result indicated that here is significant difference between self-concept of science \& arts group students.

According to the study of Conroy (2003) achievement motivation is working as another British Journal of Arts and Social Sciences motivational factor for the effective functioning of creativity. Self- concept also is important with regard to achievement motivation, because, people who feel favorably about themselves tend to work hard.

\section{AIM OF THE STUDY}

The aim of the present research study was to find out the effect of in self concept and emotional intelligence of arts and science faculty students.

\section{OBJECTIVE OF THE STUDY}

- To find out the difference in self concept of arts and science faculty students.

- To find out the difference in emotional intelligence of arts and science faculty students. 
Self concept and Emotional intelligence: A comparative study of Arts and Science college students

\section{HYPOTHESIS OF THE STUDY}

- There is significant difference in self concept between the arts and science faculty students.

- There is significant difference in emotional intelligence between the arts and science faculty students.

\section{VARIABLES}

- Independent variable -
A) Gender - 1) Male 2) Female
B) Faculty - 1) Arts 2) Science

- Dependent variable -
A) Self-concept
B) Emotional intelligence

\section{METHODOLOGY}

\section{Sample}

The sample of the study consists of 120 students (60 male and 60 female) Sample of the study was selected simple random sampling from the college going students of jalgaon Dist. Their age range was $18-22$ years. Thus, the male and female student's ratio was 1:1.

\section{Tools}

For measuring some independent variables and the dependent variable following standardized tests and scale was used.

\section{Self concept test}

This test was constructed and standardized by Dr. Sherry, Verma and Goswami. This test consists of 48 items. The statements of the test are simple and declarative about self, seeking responses in YES or NO. Responses are obtained on an answer sheet and this booklet can be used again and again. There is no time for completing the test but the respondent is advised to complete the test as quickly as possible. Generally it takes a respondent about 20 minutes to complete the test. This test consists of 08 dimensions of self concepts. 


\section{Emotional Intelligence}

This test was constructed and standardized by Dr. HYDE, PETHE AND DHAR (2002). This test consists of 34 items. This test consists of 10 dimensions of self concepts. The split- half reliability coefficient has been found to be 0.88 .

The Validity has been found to be 0.93 .

\section{Research Design -}

Since, there were two independent variable and each variable was classified at two levels. A 2x2 factorial design was used.

\section{RESULT AND DISCUSSIONS}

In this part investigator has explained the result related to statistical analysis and hypothesis.

- Hypothesis no -01There is significant difference in Self-concept between the arts and science faculty students.

Table no - 01 Faculty wise comparison on Self-concept

\begin{tabular}{|l|l|l|l|l|l|}
\hline Faculty & N & Mean & SD & t & Sig. Level \\
\hline Arts & 60 & 162.63 & 15.48 & 1.05 & NS \\
\hline Science & 60 & 159.83 & 13.94 & & \\
\hline
\end{tabular}

Table no 1 shows the self concept level among arts and science faculty students. The researcher found that the mean value on self concept of arts faculty students was 162.63 and SD is 15.48. Similarly the mean value on self concept of science faculty students was 159.83 and SD is 13.94. The calculate " $t$ " value is 1.05 . It is not significant at 0.01 levels. It is indicates that there is no significant difference in self concept between the arts and science faculty students. That's why above hypothesis is rejected. 
Faculty wise comparison on Self-concept

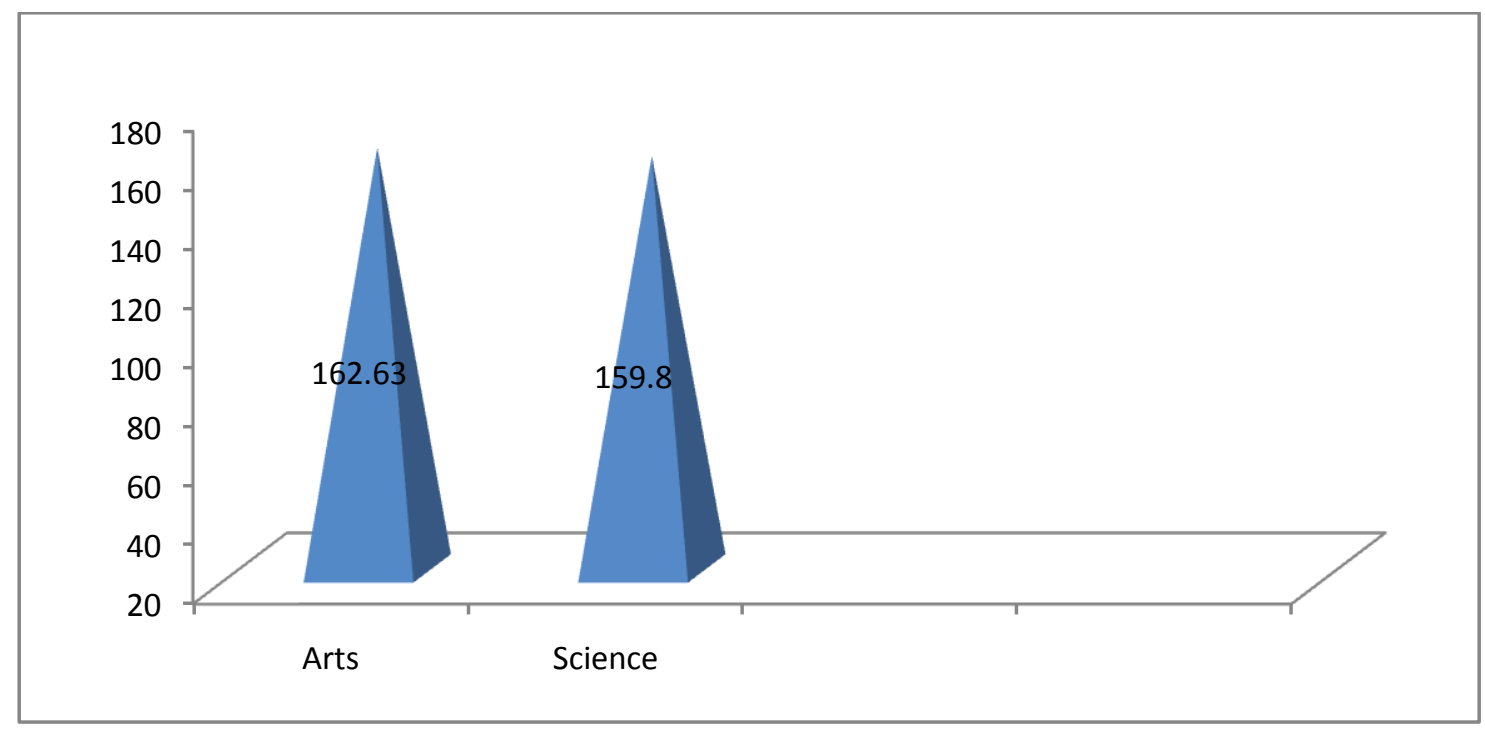

\section{Graph no 01}

- Hypothesis no- 2 There is significant difference in emotional intelligence between the arts and science faculty students.

Table no - 02 Faculty wise comparisons on Emotional intelligence

\begin{tabular}{|l|l|l|l|l|l|}
\hline Faculty & N & Mean & SD & t & Sig.Level \\
\hline Arts & 60 & 76.56 & 12.88 & 4.70 & 0.01 \\
\hline Science & 60 & 84.96 & 4.99 & & \\
\hline
\end{tabular}

Table no 1 shows the self concept level among arts and science faculty students. The researcher found that the mean value on emotional intelligence of arts faculty students was 76.56 and SD is 12.88. Similarly the mean value on emotional intelligence of science faculty students was 84.96 and SD is 4.99. The calculate " $t$ " value is 4.70. It is significant at 0.01 levels. It is indicates that there is significant difference in emotional intelligence between the arts and science faculty students. That's why above hypothesis is accepted. 


\section{Faculty wise comparison on Emotional intelligence}

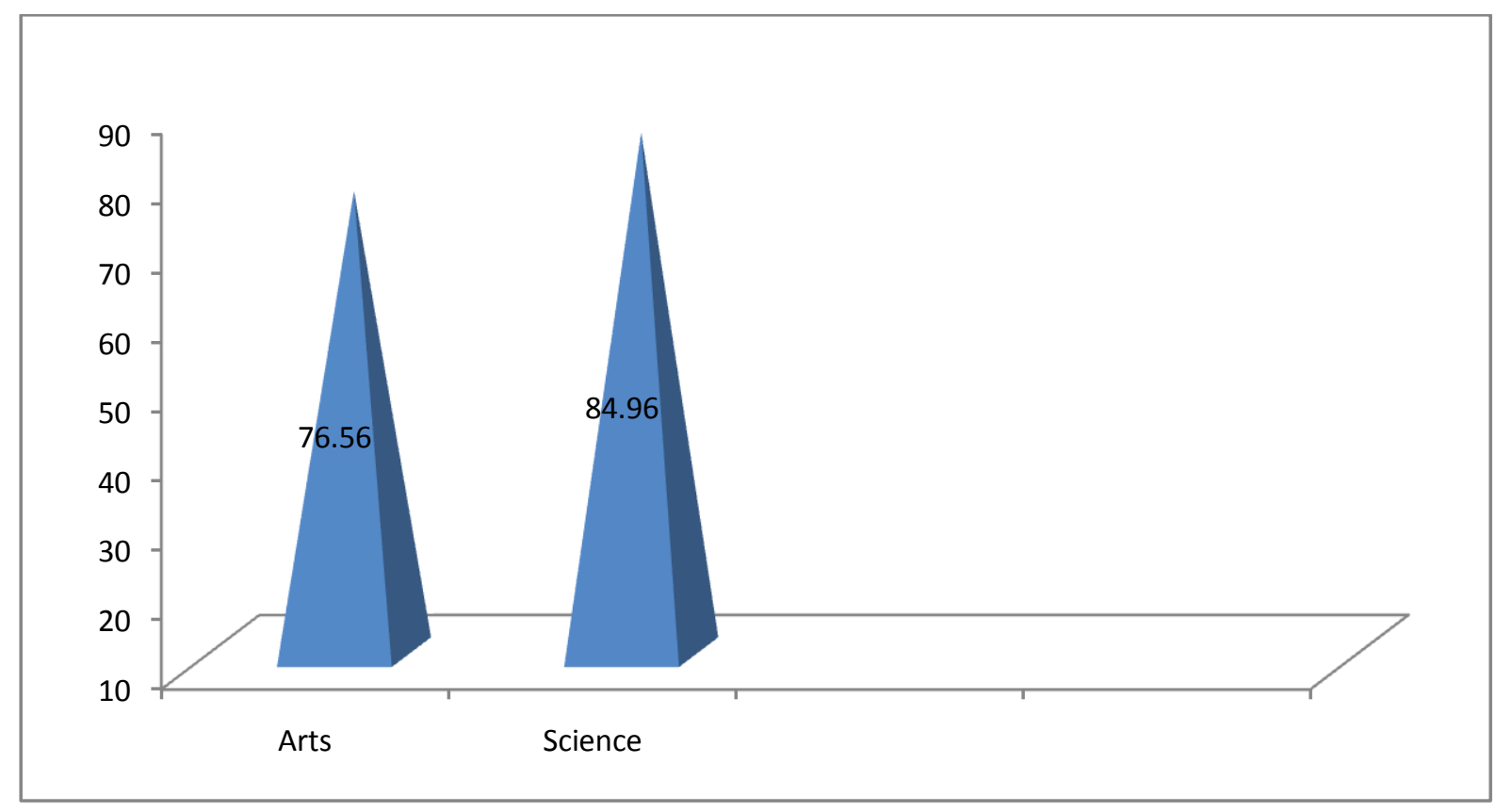

\section{Graph no - 02}

\section{DISCUSSIONS -}

The aim of the present study was to find out the effect of in self concept and emotional intelligence of arts and science faculty students.

First hypothesis Result obtained after analysis it data are show table no -1 reveals that no significant difference was found between arts and science faculty students with reference to their self concept. That's why above hypothesis is rejected.

Second hypothesis result obtained after analysis it data are show table no- 2 reveals that there would be significant difference was found between arts and science faculty students with reference to their emotional intelligence. This significant " $t$ " value (4.70) indicates that faculty significantly affects the emotional intelligence. The mean value of emotional intelligence of arts faculty students is 76.56 , science faculty students is 84.96 . This reveals the fact that science faculty students have highest emotional intelligence than arts faculty students. The finding of the present study is in agreement with the studies conducted by Thingujam and Ram (2000) also supported these findings. They found that in their attempt of Indian adaptation of Emotional Intelligence Scale (Schutte et al, 1998) had developed Indian norms ( $=811)$ for males and females separately and found that women were significantly scoring higher than men. Another supportive study found that Mohanty and Devi. L (2010) have revealed in their study on gender differences among EI $(\mathrm{N}=60)$ that girls are more optimistic and well aware of their feelings in 
comparison to boys. Girls are more aware and understand their own feelings (Components of EI) than boys. In their study conducted on students of Faculty Science, Engineering Faculty, College of Physical Education, Faculty of Law, Faculty of Letters, Faculty of Fine Arts and Heath Science; they found that determined that there are relations between academic achievements and especially understanding own emotions and Emotion Management sub- scales of Emotional Intelligence. That is why the above finding can be supported by the conclusion of the studies carried out by Erdoğdu and Kenarlı (208).

\section{CONCLUSION -}

- There is no significant difference in Self-concept between the arts and science faculty students.

- There is significant difference in emotional intelligence between the arts and science faculty students. Science faculty students have highest emotional intelligence than arts faculty students.

\section{REFERENCE -}

1. Borude, R.R. (2005) Research Methodology. Chhya Publication, Aurangabad.

2. Codaty Jyostana. (2004) Understanding Emotional Intelligence. Pustak Mahal, Delhi.

3. Guilford, J. P. (1956). Fundamental statistics in Psychology and Education. New York, McGraw Hill.

4. Guilford, J. P. (1966). The nature of human intelligence. New York; McGraw Hill.

5. James, W. (1890). The principles of psychology, 2nd Vol. New York: Smith.

6. Morgan.C.T. (2001) Introduction to Psychology, Tata McGraw Hill Publications.

7. Mundada, Khalane (2013) Fundamental of Psychology, $1^{\text {st }}$ Ed, Atharv Publication, Jalgaon.

8. Pawar .B.S. (2011) "Self esteem, Self concept and Self efficacy among visually, hearing impaired and orthopedically disabled adolescents of khandesh region". Ph.D.Thesis. Thesis. North Maharashtra University, Jalgaon.

9. Shirsath, Javeed. (2010) "A study of self concept among senior college students those who performing yoga and those who not perform yoga" Indo-Indian journal of social science researches, $2^{\text {nd }}$ Issue (6) 125-127. 